ఠ

\title{
Fixed Ratio versus Lower Limit of Normality for Diagnosing COPD in Primary Care: Long-Term Follow-Up of EGARPOC Study
}

This article was published in the following Dove Press journal: International Journal of Chronic Obstructive Pulmonary Disease

\author{
Montserrat Llordés $\mathbb{D}^{1}$ \\ Angeles Jaen (D) ${ }^{2}$ \\ Elba Zurdo $\mathbb{D}^{1}$ \\ Montserrat Roca' \\ Inmaculada Vazquez' \\ Pere Almagro $\mathbb{D D}^{3}$ \\ On behalf of the EGARPOC \\ collaboration group \\ 'Terrassa Sud Primary Care Center, \\ Hospital Universitari Mutua Terrassa, \\ University of Barcelona, Barcelona, Spain; \\ ${ }^{2}$ Fundació Docència i Recerca Mutua \\ Terrassa, Barcelona, Spain; ${ }^{3}$ Internal \\ Medicine Service, Hospital Universitari \\ Mutua Terrassa, University of Barcelona, \\ Barcelona, Spain
}

Correspondence: Montserrat Llordés Terrassa Sud Primary Care Center, Hospital Universitari Mutua Terrassa,

Avenida Santa Eulalia $s / n$, Terrassa,

Barcelona 08223, Spain

$\mathrm{Tel}+34937855161$

$\mathrm{Fax}+34937314952$

Email mllordes@mutuaterrassa.cat
Purpose: The best criterion for diagnosing airway obstruction in COPD, fixed ratio (FR: FEV1/FVC $<0.7)$ or lower limit of normality (LLN), remains controversial. We compared the long-term evolution of COPD patients according to the initial obstruction criteria.

Patients and Methods: Between 2005 and 2008, we evaluated 1728 subjects over 45 years of age with smoking history, pertaining to a primary care center. A total of 424 patients were obstructive by FR, after a bronchodilator test. Of those, 289 patients met obstruction criteria for both FR and LLN and were considered concordant patients $(\mathrm{FR}+\mathrm{LLN}+)$, while 135 patients were obstructive by FR but non-obstructive by LLN and were defined as discordant patients (FR+LLN-).

Results: Forty-eight patients (11.3\%) were lost in follow-up, and 158 died (37.3\%). After a median time of 120.4 months (IQR 25-75\%: 110.2-128.8), 215 patients were spirometrically reevaluated. The annualized loss of FEV1/FVC was greater in discordant (FR+LLN-) patients [0.54 (0.8) vs $0.82(0.7) ; \mathrm{p}=0.008]$, while $81 \%$ became concordant $(\mathrm{FR}+\mathrm{LLN}+)$ during the follow-up. Hospitalization for COPD exacerbations was more frequent in concordant $(\mathrm{FR}+\mathrm{LLN}+)$ patients $(1.57 \pm 3.51$ vs $0.77 \pm 2.29 ; \mathrm{p}=0.002)$. Adjusting for age, concordant $(\mathrm{FR}+\mathrm{LLN}+)$ patients had greater COPD mortality (HR: 2.97; CI 95\%: 1.27-7.3; $\mathrm{p}=0.02)$.

Conclusion: LLN seems to be less useful for COPD diagnosis in primary care. Discordant (FR+LLN-) patients lost more FEV1/FVC during their evolution and tended to become concordant. LLN predicted COPD hospitalizations and mortality more poorly.

Keywords: COPD, lower limit of normality, fixed ratio, prognosis, airway obstruction, mortality

\section{Plain Language Summary}

Chronic Obstructive Pulmonary Disease (COPD) is a very common yet largely undiagnosed disease. We believe that the best environment to fight against this underdiagnosis is the primary care level, by enabling diagnosis in earlier stages of the disease. The Global Initiative for Chronic Obstructive Lung Disease international strategy (GOLD) advocates systematic case-finding in primary care and performing spirometry only in symptomatic patients with risk factors to make earlier diagnosis of COPD. Nevertheless, the best criterion for diagnosing airway obstruction, fixed ratio (FR) or lower limit of normality (LLN), continues to be debatable.

Our study is based on the long-term follow-up (8-11 years) of 424 patients included in the EGARPOC study, who were classified according to the two diagnostic criteria. Analyzing their clinical and functional evolution, we came to the conclusion that FR is more useful for the diagnosis of COPD in the primary health care setting. 


\section{Introduction}

Chronic obstructive pulmonary disease (COPD) is universally underdiagnosed, and several epidemiological investigations have shown that $75 \%$ or more of patients with COPD remain undiagnosed, without substantial changes in recent years. ${ }^{1,2}$ The Global Initiative for Chronic Obstructive Lung Disease (GOLD) advocates systematic case-finding in primary care and performing spirometry only in symptomatic patients with risk factors for making an earlier COPD diagnosis, although the best approach-population screening or case-finding - continues to be debatable..$^{3-5}$

On the other hand, the best criteria for defining airflow obstruction in COPD patients, remains an unresolved issue. GOLD recommended as a spirometric criterion a postbronchodilator fixed ratio (FR) of FEV1/FVC $<0.70$, while other authors consider the lower limit of normality (LLN) to be more reliable. ${ }^{3,6-8}$

Nevertheless, FR and LLN are two ways to dichotomize a continuous variable. Some subjects with risk criteria for COPD such as smoking history may have symptoms, exacerbations, and radiological alterations, before reaching accepted spirometric criteria for airway obstruction. ${ }^{9,10}$ These patients could be in an initial stage of the disease, and during their evolution, some will meet the obstruction criteria for the FR before those for LLN. Using the LLN criterion - usually more restrictive - may delay diagnosis and treatment, including a more aggressive approach to smoking cessation, in some milder patients. This is in contrast to the more recent recommendations for the diagnosis of other chronic diseases, such as hypertension, dyslipidemia, and diabetes. ${ }^{11,12}$ These new recommendations are based on the increased risk of future events, while secondarily creating an increase in the number of affected people previously deemed healthy. ${ }^{13,14}$

In a previous study, performed to assess the prevalence of COPD among smokers in primary care, we studied 1,738 subjects, of whom 424 had airway obstruction according to the fixed index. ${ }^{15}$ In this study, 289 individuals had a concordant diagnosis both for the fixed ratio and for the LLN (FR + and LLN +), and 135 a discordant diagnosis, obstructive with fixed ratio but non-obstructive criteria by LLN (FR + and LLN -). There were no individuals deemed obstructed with LLN with FEV1/FVC $>0.7$.

The main aim of the present study was to assess the best criteria for diagnosing airflow obstruction in COPD screening studies performed in primary care. For this purpose, we evaluated the long-term follow-up spirometric progression of FEV1/FVC and the clinical impact with respect to hospitalizations and mortality according to their airway obstruction definition in the initial study.

\section{Patients and Methods}

This is an observational cohort study, performed with a population-based screening research project previously conducted in a primary care center (EGARPOC study). The methodology is broadly detailed in the previous study. ${ }^{15}$ Briefly, all subjects older than 45 with a history of smoking and belonging to a primary care center were screened. In all respondent subjects, smoking history and previous diagnosis of COPD were collected. The presence of respiratory symptoms and professional exposure was determined with validated questionnaires. ${ }^{16,17}$ All included patients performed a baseline spirometry, and for those with an FEV1/FVC $<0.7$, the test was repeated after inhalation of $400 \mu \mathrm{g}$ of salbutamol. Patients who continued with an FEV1/FVC $<0.7$ after bronchodilator testing were considered obstructive. Of these, $97 \%$ referred some type of respiratory symptoms in the validated questionnaires. Subsequently, in all patients, the LLN for FEV1/FVC was calculated using the GLI 2012 equations. ${ }^{18}$ Since in this study all patients with airflow obstruction according to the LLN were obstructive by the fixed ratio, the patients were classified into two groups: a) concordant-obstructive by FR (FR +) and LLN (LLN +), or b) discordant-obstructive by FR but not by LLN (LLN-). Comparisons were made between concordant (FR+LLN + ) and discordant (FR +LLN-) patients. After their inclusion, the patients' usual physicians were informed of the spirometry results without subsequent intervention of the researchers in treatment or follow-up.

For the present study, we tried to contact all patients diagnosed with an FR $<0.7$ in the previous study. Patients who agreed to participate were given appointments and selfadministered questionnaires to collect information about filiation, smoking habits, COPD Assessment Test (CAT), mMRC dyspnea scale, and BODEX index, as well as the phenotype according to the Spanish COPD strategies. ${ }^{19-23}$ We also collected the present treatment of COPD, data on the comorbidity measured by the Charlson index and other relevant comorbidities not included in the Charlson index. The number of hospitalizations and exacerbations for COPD was calculated using the electronic medical reports shared between primary and hospital care. Exacerbations were defined as moderate (when systemic corticosteroids and/or antibiotics were administered at the outpatient level) or severe (when hospital consultation was required) during the evolution. ${ }^{23,24}$ Subsequently, trained 
personnel performed post-bronchodilator spirometry with the Ergometrix, Blue Spiro USB model, following international guidelines and the reference values of Roca et al. ${ }^{25,26}$ In the deceased patients, the date and cause of the death were noted. Cause-specific mortality was first attributed to a specific cause of death and then grouped by a general pathophysiological category (cardiovascular, respiratory, cancer, or other). In patients with the loss of follow-up, the last date on which their vital status was noted in their medical history was considered. After this moment, the data of these patients were censored.

The study was performed following the international STROBE normative. $^{27}$ (Table S1)

Both the initial and the follow-up protocol were approved by the Ethics and Clinical Trials Committee of the Mutua Terrassa University and all patients signed the informed consent. The deceased patients and those who were lost in the follow-up had granted their signed informed consent in the previous study, authorizing access to the hospital database for follow-up.

\section{Statistical Analysis}

Qualitative variables were expressed as absolute frequencies and percentages, while quantitative variables were summarized as mean and standard deviation (SD) in the case of normal distribution, or median and interquartile range otherwise. Comparison among means was made with the Student's $t$-test for independent samples and the non-parametric test (Mann-Whitney U) for variables not distributed normally. Either the X2 test or the Fisher exact test was used for comparison of proportions. For survival analysis, the date of the first spirometry was considered as the inclusion date, while the date on which the spirometry was repeated (survivors) or the date of death or loss of follow-up was considered the final follow-up date. Hazard ratios (HR) and 95\% confidence intervals (CI) for survival time were calculated with Cox regression models, and statistical significance was obtained with the long-rank test and 95\% CI. Multivariate analysis for mortality was also calculated with Cox logistic regression analysis. Variables entered in the model were chosen based on univariant and clinical significance. Different models were created to analyze the different causes of mortality grouped as respiratory, cardiovascular, or neoplastic. In all of these concordant or discordant status according to FR or LLN was considered the dependent variable. Spirometric changes during evolution were annualized to avoid bias due to different follow-up times between spirometries.

Statistical analyses were performed using the IBM SPSS Statistics 20 and Stata/SE 13.0 programs. A p value inferior to 0.05 or a $95 \%$ CI that did not include the unit was considered statistically significant.

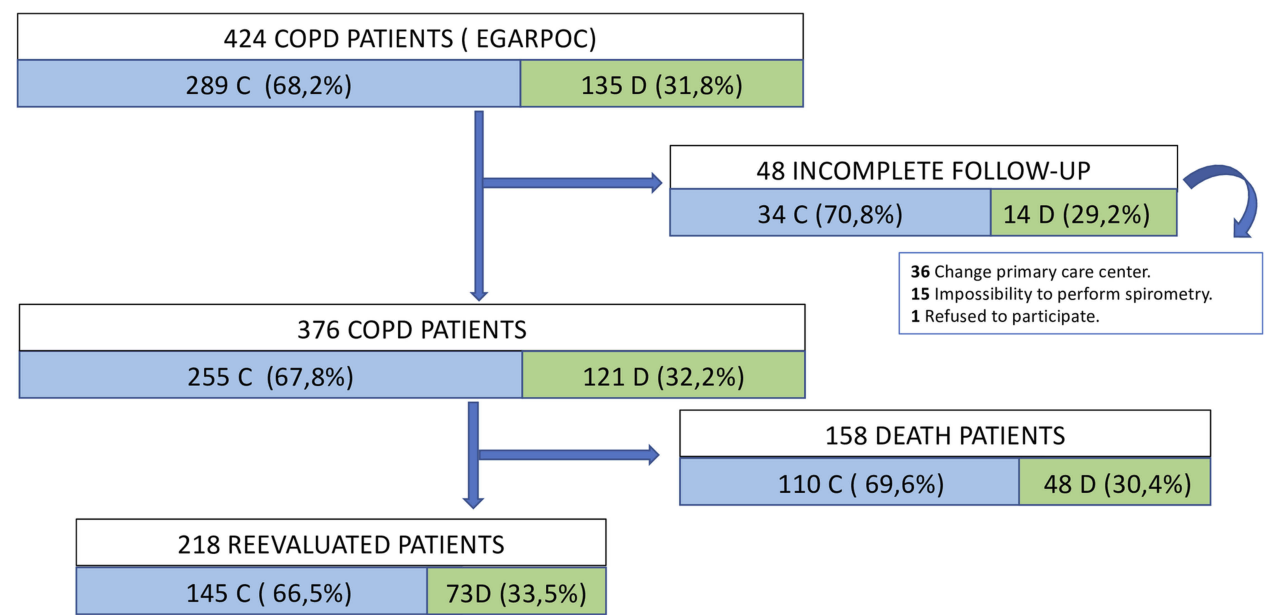

3 POOR QUALITY SPIROMETRY

Figure I Evolution of the 424 COPD patients of EGARPOC study during long-term follow-up.

Note: C, concordant patients; D, discordant patients. 


\section{Results}

The initial study was conducted between January 2005 and December 2008, while the follow-up and spirometries were completed between January 2015 and July 2018. Of the 1,728 patients initially studied, 424 had a FEV1/FVC $<0.7$. Of these, 289 were considered concordant (FR+LLN+) and 135 discordant (FR+LLN-). The median time between the two spirometric evaluations was 3,648 days (IQR 25-75\%: 3,340-3,904) (Figure S1).

Forty-eight patients (11.3\%) were lost in follow-up. These patients were similar to the rest in terms of gender, age, spirometric data, smoking history, and the number of concordant and discordant subjects (Table S2).

Table I Characteristics of Patients with Complete Follow-Up According to Their Classification at Baseline

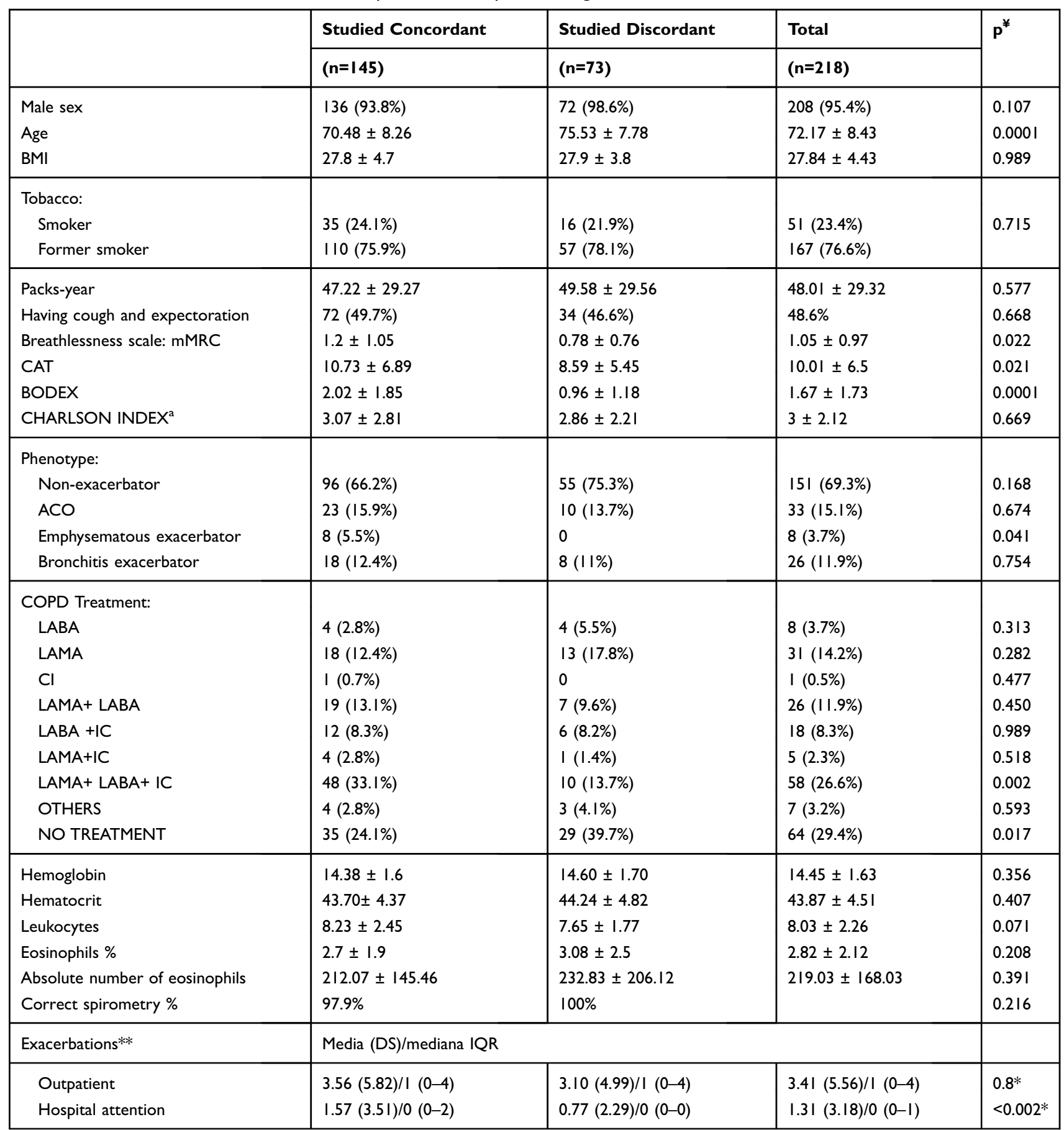

Notes: *Mann-Whitney U. **Non-parametric analysis. ${ }^{a}$ Adjusted by age. ${ }^{*}$ Value of comparisons by Chi-square/Fisher test or $t$-test. 
Another 158 patients (37.3\%) died during follow-up (Figure 1). The median follow-up for total patients was 2,426 days (IQR 25-75: 2,272-3,795). In total, a new spirometry was arranged for 218 patients. The mean age of patients with complete follow-up was 72.2 years $( \pm 8.4)$, with 208 (95.4\%) being male. Comorbidity measured with age-adjusted and non-adjusted Charlson index was similar between groups. The individualized chronic diseases included in the Charlson index, and others relevant comorbidities, are detailed in Table S3. The rest of the characteristics are detailed in Table 1.

\section{Pulmonary Function Evolution}

In 3 of the 218 patients, follow-up spirometry did not reach the required quality levels and the resulting values were considered missing for spirometric analysis. At the time of the initial spirometry, discordant patients had better levels of FEV1 mL $[2,158( \pm 684)$ vs $2,425( \pm 530) ; \mathrm{p}=0.004]$, of FEV1\% [70.1 $( \pm 18.7)$ vs $83.1( \pm 14.6) ; \mathrm{p}=0.01]$ and $\mathrm{FEV} 1 / \mathrm{FVC}$ ratio $[58.6$
$( \pm 8)$ vs $67.3( \pm 1.9) ; p<0.0001]$ than the concordant patients, with similar levels of FVC $\mathrm{mL}$ and FVC \% (Table 2).

In the follow-up spirometries, the FEV1 values (expressed both in absolute and percentage values), the FVC \%, and the FEV1/FVC ratio were also significantly better in initially discordant patients. When analyzing the differences between initial and final spirometries, the annualized differences were similar for FEV1 and FVC, although in the discordant patients the annualized FEV1/ FVC ratio decreased significantly compared to concordant patients [0.54 $( \pm 0.8)$ vs $0.82( \pm 0.7) ; p=0.008]$ (Figure 2). This meant that $81 \%$ of the patients discordant at the initial evaluation became concordant during the follow-up, while only $4 \%$ of the patients concordant at the beginning were discordant at the end of the study.

The loss of annualized lung function was inversely related to the lower level of severity according to the spirometric classification of the initial GOLD. That is, the more mildly affected patients presented greater loss of lung

Table 2 Spirometry Differences Between Concordant and Discordant Patients

\begin{tabular}{|c|c|c|c|c|}
\hline & Studied Concordant $(n=\mid 42)$ & Studied Discordant ( $n=73$ ) & Total $(n=2 \mid 5)$ & $\mathbf{p}^{*}$ \\
\hline \multicolumn{5}{|l|}{ Initial } \\
\hline FEVI $\mathrm{mL}$ & $2158(684)$ & $2425(530)$ & 2249 (647) & 0.004 \\
\hline FEVI\% & 70.1 (I8.7) & 83. I (14.6) & 75 (18.3) & 0.01 \\
\hline $\mathrm{FVC} \mathrm{mL}$ & $3.632(982)$ & $3588(744)$ & 3617 (907) & 0.7 \\
\hline FVC \% & 87.5 (19.4) & 88.5 (15.9) & $87.9(18.2)$ & 0.7 \\
\hline FEVI/FVC & $58.6(8)$ & $67.3(1.9)$ & $61.6(7.8)$ & $<0.0001$ \\
\hline \multicolumn{5}{|c|}{ Final follow-up } \\
\hline FEVI $\mathrm{mL}$ & $|84|(626)$ & $2.067(492)$ & $1918(593)$ & $<0.0001$ \\
\hline FEVI\% & $61(17.5)$ & $71.9(12.3)$ & $64.7(17)$ & $<0.0001$ \\
\hline $\mathrm{FVC} \mathrm{mL}$ & $3436(922)$ & $3500(742)$ & $3547(865)$ & 0.7 \\
\hline FVC $\%$ & $82.7(18.5)$ & 88 (15.9) & 84.5 (17.8) & 0.04 \\
\hline FEVI/FVC & $53.2(9.2)$ & $59.2(6.8)$ & $55.2(6.8)$ & $<0.0001$ \\
\hline \multicolumn{5}{|l|}{ Differences } \\
\hline FEVI mL & $-3 \mid 7.3(356.4)$ & $-357.8(299.1)$ & $-331(338)$ & 0.4 \\
\hline FEVI\% & $-9.7(11.6)$ & $-11.2(10.5)$ & $-10.2(11.2)$ & 0.3 \\
\hline $\mathrm{FVC} \mathrm{mL}$ & $-196.1(645)$ & $-88(466)$ & $-159.6(592)$ & 0.2 \\
\hline FVC \% & $-4.8(16.3)$ & $-0.6(13.5)$ & $-3.4(\mid 5.5)$ & 0.055 \\
\hline FEVI/FVC & $-5.4(7.6)$ & $-8.1(6.2)$ & $-6.3(7.2)$ & 0.009 \\
\hline \multicolumn{5}{|c|}{ Annualized differences } \\
\hline FEVI $\mathrm{mL}$ & $-31.5(37.6)$ & $-35.9(30.8)$ & $-33(35.4)$ & 0.4 \\
\hline FEVI\% & $-I(2.2)$ & $-I . I(I . I)$ & $-I(I .2)$ & 0.4 \\
\hline $\mathrm{FVC} \mathrm{mL}$ & $-18.6(64.2)$ & $-8.3(46)$ & $-15(58.8)$ & 0.2 \\
\hline FVC \% & $-0.47(1.7)$ & $-0.03(1.4)$ & $-0.32(1.6)$ & 0.052 \\
\hline FEVI/FVC & $-0.54(0.8)$ & $0.82(0.7)$ & $0.63(0.7)$ & 0.008 \\
\hline
\end{tabular}

Notes: ${ }^{*} \mathrm{p}$ value by $t$-test for independent samples. Values expressed as mean (standard deviation). 

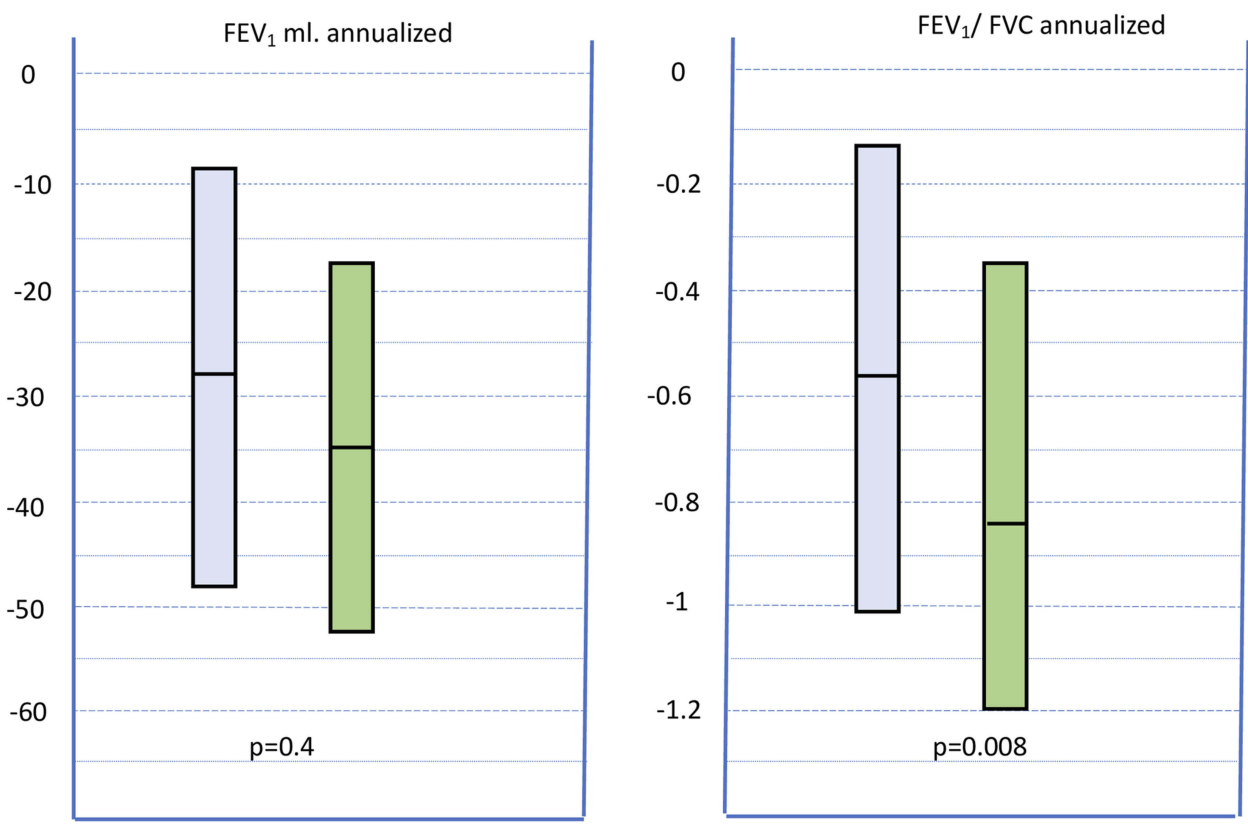

Figure 2 Annualized differences of FEVI and FEVI/FVC between concordant (blue) and discordant (green) patients.

function for both FEV1 and FVC, expressed in both $\mathrm{mL}$ and as a percentage (Table 3$)$. A total of 87 patients $(40.5 \%)$ lost more than $40 \mathrm{~mL} /$ year of FEV1 and were considered rapid decliners. The proportion of rapid decliners was greater in discordant patients, although this value did not reach statistical significance $(38.0 \%$ concordant vs $45.2 \%$ discordant; $\mathrm{p}=0.4)$. The annualized and grouped losses of pulmonary function according to the status of the patient at inclusion (concordant or discordant) are detailed in Figure 3.

\section{Prognosis}

Concordant patients required a greater number of hospital admissions for COPD exacerbation than did discordant patients [1.57 $( \pm 3.51)$ vs $0.77( \pm 2.29) ; \mathrm{p}=0.002]$.

During the follow-up, 158 patients $(37.26 \%)$ died. Of these, 110 were concordant and 48 discordant $(\mathrm{p}=\mathrm{ns})$.

Table 3 Loss of Lung Function According to Initial Spirometric Severity

\begin{tabular}{|l|l|l|l|l|}
\hline & Mild & Moderate & Severe/Very Severe & \multirow{2}{*}{ p $^{*}$} \\
\cline { 2 - 4 } & $\mathbf{( n = 8 3 )}$ & $\mathbf{( n = 1 0 9 )}$ & $\mathbf{( n = 2 3 )}$ & \\
\hline FEVI mL & $-47.7(36.8)$ & $-25.6(31.9)$ & $15(27.1)$ & $<0.001$ \\
FEVI\% & $-1.6(1.1)$ & $-0.7(1.1)$ & $-0.4(0.8)$ & $<0.001$ \\
FVC mL & $-32.8(63.1)$ & $-61.8(538)$ & $-20.4(536)$ & 0.002 \\
FVC \% & $-0.9(1.8)$ & $-0.7(1.4)$ & $-0.01(1.2)$ & $<0.001$ \\
FEVI/FVC & $-0.7(0.8)$ & $-0.6(0.7)$ & $-0.4(0.6)$ & 0.4 \\
\hline
\end{tabular}

Note: *p value of the comparison of groups by ANOVA test.
The overall median follow-up was 3,426 days (IQR 25-75\%: 2,272-3,794) - 3,648 (IQR 25-75\%: 3,342-3,967 ) for the alive and 2,043 (IQR 25-75\%: 1,182-3,203) for the deceased patients. Variables associated with mortality were the values for FEV1, FVC, and FEV1/FVC in the initial spirometry, age at inclusion, and the smoking history measured with the number of package-years (all $\mathrm{p}<0.0001$ ), while gender and concordance status were non-significant (Table S4). In the multivariate analysis, both age and FEV1\% and the number of package-years retained their statistical significance, after adjustment for gender and concordant status (Table S5). The only significant difference related with mortality between concordant and discordant deceased patients was age at study inclusion [75.91 years $( \pm 9.6)$ vs $80.35( \pm 7.7) ; \mathrm{p}=0.005]$.

Table 4 shows the causes of death of the 158 patients according to whether they were concordant or discordant at study inclusion. The main causes of death were neoplasm in 61 patients (40 of them due to lung cancer), followed by COPD (28 patients) and cardiovascular disease (19 patients). Figure 4A and B show the Kaplan-Meier curves for global and COPD mortality, both crude and age-adjusted, between concordant and discordant patients. Age-adjusted global and COPD mortality were higher in concordant patients (HR: 1.46; IC 95\%: 1.03-2.07; p=0.03), (HR:2.97; CI 95\% $1.2-7.3 ; \mathrm{p}=0.02$ ), respectively (Figure 4B). Survival analyses for other specific causes of mortality were shown Figure S2. 


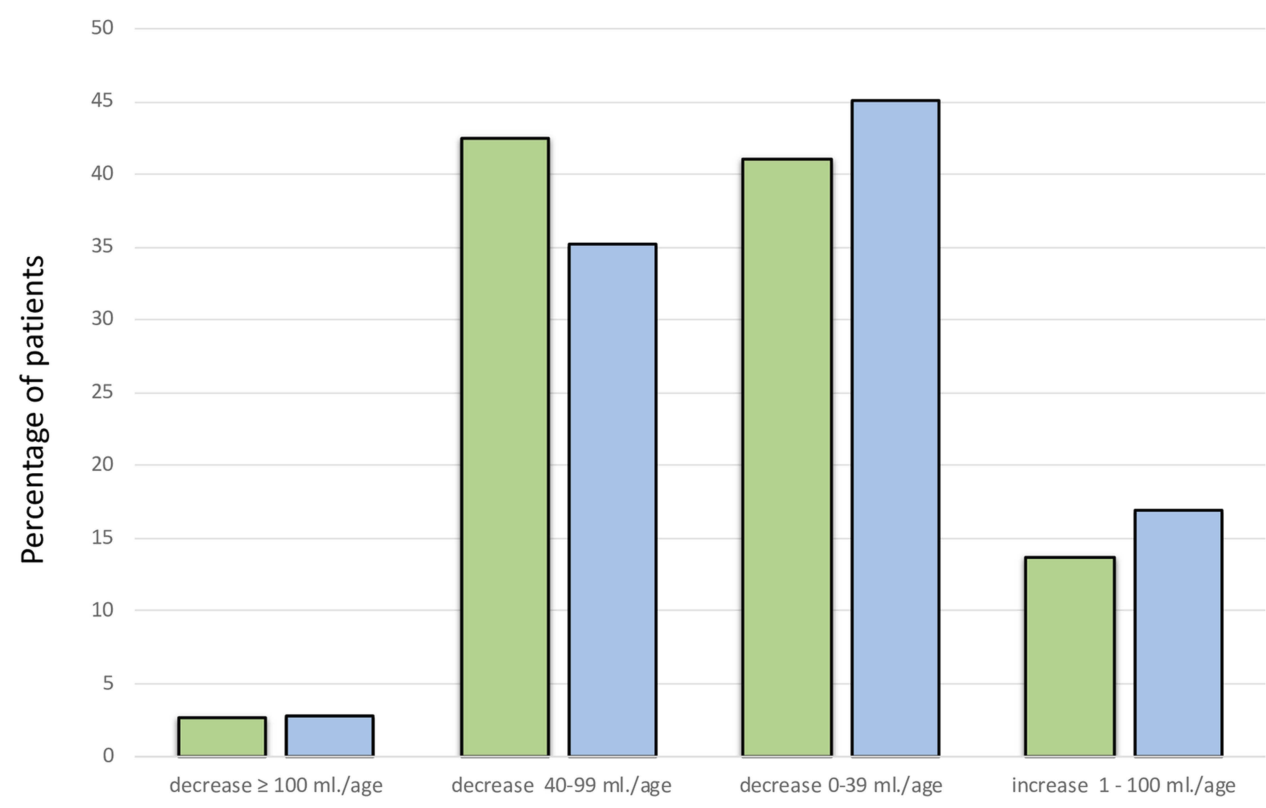

Figure 3 Grouped annualized differences of FEVI $\mathrm{mL}$. Note: Concordant (blue) and discordant (green) patients.

\section{Discussion}

The main conclusion of our study is that in case-finding strategies the confirmation of airway obstruction with FR is sufficient for a diagnosis of COPD, regardless of the LLN values. In our cohort, most of the patients discordant at baseline evolved to concordant at follow-up. This suggests that the use of LLN in this population delays the diagnosis. In contrast, in our population FR predicted hospitalizations for COPD exacerbations and COPD mortality more accurately.

The long follow-up in our cohort allowed us to explore the evolution of respiratory function in both groups of patients. Similarly, from the data of the ECLIPSE study the loss of lung function is heterogenous between patients. ${ }^{28}$ The annualized loss of FEV1 $\mathrm{mL}$ ( $33 \mathrm{~mL} /$ year), and the number of patients with a loss greater than $40 \mathrm{~mL} /$ year $(38 \%)$, are practically identical in the two studies. Our work also confirms the greater loss of FEV1 in $\mathrm{mL}$ in patients with milder stages of spirometric severity according to GOLD. Although it is logical to assume that patients with higher levels of FEV1 $\mathrm{mL}$ lose more during follow-up, in our study this loss was also observed when FEV1 values were expressed as a percentage of the predicted value. Our data also show that the FEV1/FVC ratio decreases over time, and that this decrease is more pronounced in discordant patients. This meant that $81 \%$ of discordant patients in the initial evaluation became concordant during the follow-up.

Table 4 Causes of Death in Concordant and Discordant Patients

\begin{tabular}{|c|c|c|c|c|}
\hline & Concordant & Discordant & Total Death & \multirow{2}{*}{$\begin{array}{l}\mathrm{p}^{*} \\
(\text { Total death } \mathrm{p}=0.42)\end{array}$} \\
\hline & $110(69.6 \%)$ & 48 (30.4\%) & 158 (100\%) & \\
\hline Neoplasia & $44(40 \%)$ & $17(35.42 \%)$ & $6 \mathrm{I}(38.6 \%)$ & 0.586 \\
\hline Pulmonary neoplasia & $29(26.4 \%)$ & II (22.91\%) & $40(25.3 \%)$ & 0.647 \\
\hline Other neoplasia & 15 (13.64\%) & $6(12.5 \%)$ & 21 (13.29\%) & 0.847 \\
\hline COPD & $28(25.46 \%)$ & $10(20.83 \%)$ & 38 (24.05\%) & 0.414 \\
\hline Cardiovascular diseases & 19 (17.27\%) & $8(16.67 \%)$ & 27 (17.09\%) & 0.768 \\
\hline Other diseases & $13(11.82 \%)$ & 9 (I8.75\%) & $22(13.93 \%)$ & 0.366 \\
\hline Unknown cause & $6(5.45 \%)$ & $4(8.33 \%)$ & $10(6.33 \%)$ & 0.592 \\
\hline
\end{tabular}

Note: *p value of comparison between groups by Chi-square/Fisher test. 
A GLOBAL MORTALITY

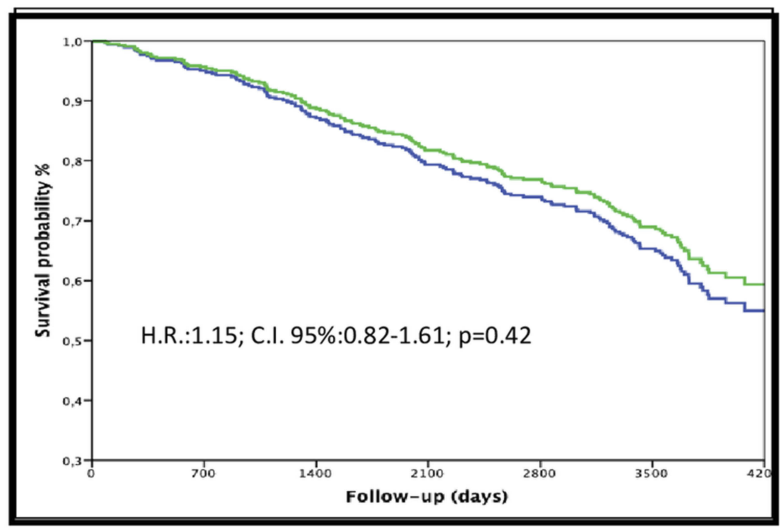

A GLOBAL MORTALITY ADJUSTED BY AGE

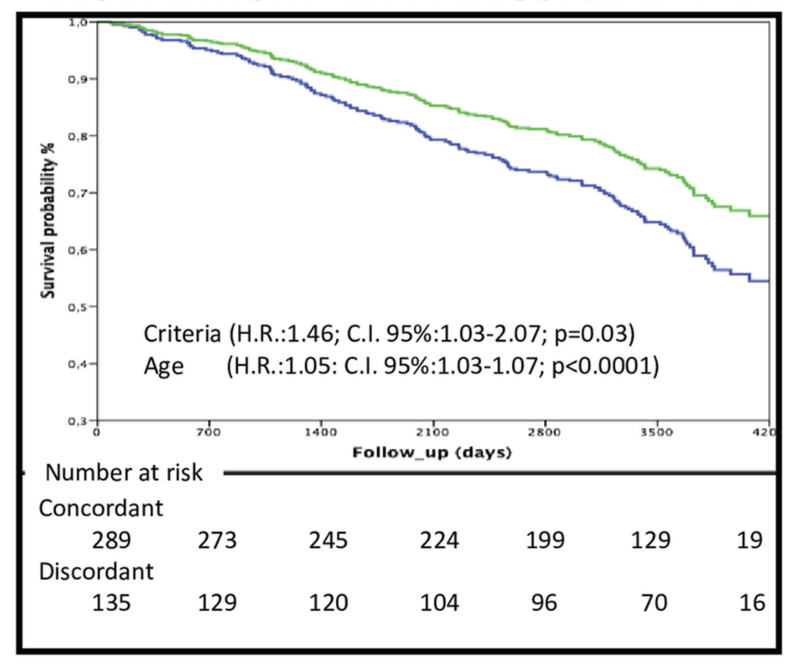

B COPD MORTALITY

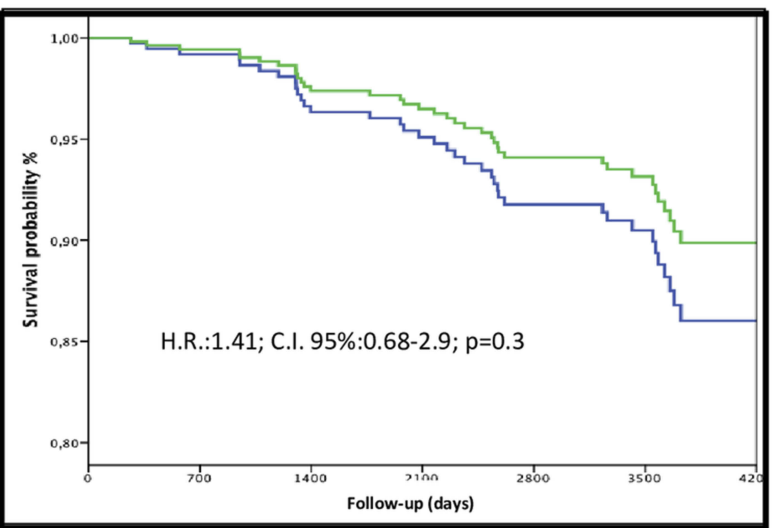

B COPD MORTALITY ADJUSTED BY AGE

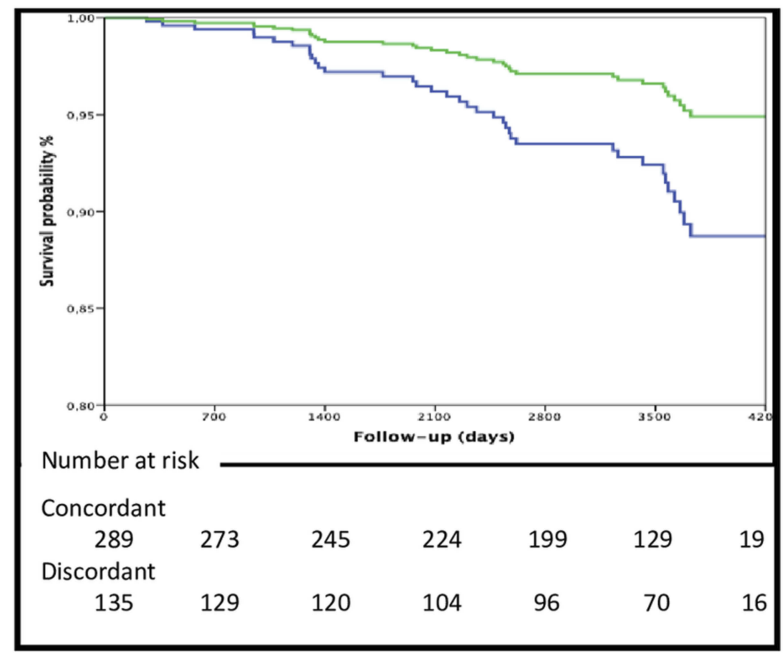

Figure 4 (A) Differences in Global Mortality crude and age adjusted between concordant (blue) and discordant (green) patients. (B) Differences in COPD mortality crude and age adjusted, between concordant (blue) and discordant (green) patients.

Previous studies carried out in the elderly population confirm that the incidence and prevalence of COPD is higher using FR than LLN. However, these studies were carried out in the general population; only $50 \%$ had a smoking history, and the presence of respiratory symptoms was not specified. ${ }^{8,29}$ In contrast, in our study, performed carried out in a population of similar age, all patients had a smoking history, and $97 \%$ were symptomatic at inclusion. We believe that in these patients the obstruction measured with FR strongly suggests the presence of disease.

Furthermore, it is well known that practically all chronic diseases including COPD are related to aging. ${ }^{30-32}$ Pulmonary aging is associated with a progressive reduction in FEV1 together with a reduction in FEV1/FVC ratio, and an increase in residual volume with preserved total lung capacity. ${ }^{32}$
In fact, FR and LLN are two ways to categorize a continuous variable (FEV1/FVC) that physiologically decreases with aging, and therefore somehow represents a simplification of the definition in a progressive disease. This is in accordance with recent studies showing that a percentage of smoking patients without formal spirometric obstruction (FEV1/FVC $\geq 0.7$ ) have symptoms, alongside radiological lesions similar to patients with established COPD, and during follow-up they reach the formal cut-off points for airway obstruction, suggestive of early stages of the disease. ${ }^{9,10,33-36}$ Both the alterations visualized in the $\mathrm{CT}$ and the presence of spirometric obstruction in COPD indicate the presence of a lesion in the airways, which reinforces the need to find a biomarker that would allow us to diagnose the disease earlier. ${ }^{37}$ In any case, in primary care spirometry 
is usually more readily available than computerized tomography.

In our population concordant patients had more severe COPD exacerbations, and greater global and COPD mortality after age adjustment. Previous studies have shown conflicting data. In the study of Luoto et al, performed in patients over 65, no differences in five-year mortality were reported between concordant and discordant subjects. ${ }^{8}$ In another study, carried out in a population of very elderly patients ( $>80$ years), 5 -year mortality was significantly higher in patients obstructive by LLN than in patients classified as obstructive by FR and nonobstructive by LLN. However, in this study FEV1 values were significantly different between groups [FEV1 $1.8( \pm 0.6)$ in LLN - vs $1.3( \pm 0.5)$ in LLN $+; \mathrm{p}<0.0001]$. Additionally, only 38 patients were obstructive by FR and LLN, and only 10 were alive at 5 years. ${ }^{7}$

Another study showed higher overall, cardiovascular, and COPD mortality in patients with obstruction regardless of the criteria used. ${ }^{38}$ Two studies based on the data from the Third National Health and Nutrition Examination Survey (NHANES III) showed that FR is a better predictor of long-term mortality than LLN. ${ }^{39,40}$ These results have been reinforced in a pooled analysis of four cohorts, in which FR was a stronger predictor than LLN for COPD mortality and hospitalizations. ${ }^{41}$ In a secondary analysis of the TIOSPIR study global mortality was similar between concordant and discordant subjects, but concordant subjects had an increased risk of cardiovascular events while discordant patients showed a greater risk of severe COPD exacerbations. However, the population differences between our study and the TIOSPIR precludes any valid comparison. ${ }^{42}$

Our study has both strengths and limitations. Among the former we may highlight the low losses of follow-up in 10 years (11\%), the long follow-up, and the homogeneity of the population studied (over 45 years of age, with a history of smoking and respiratory symptoms, belonging to a single primary care center). Regarding limitations, our study was conducted in a single geographical area and the diagnosis of COPD was much more frequent in men, which may limit its generalization to other countries. This is related to the more limited history of smoking in women in our population; in the initial study of 1,738 subjects screened only $16 \%$ were female. Second, in our study there were no patients obstructive for LLN and non-obstructive for FR. This is in accordance with the results of Bhatt et al performed in 24,000 patients in which only $0.1 \%$ of the patients were obstructive by LLN and non-obstructive by FR. ${ }^{41}$ Finally, we analyzed only 2 spirometric measures, and for this reason spirometric comparisons were described and compared annually, assuming a linear drop in respiratory function.

\section{Conclusion}

Our study suggests that FR is the best criterion for diagnosing airway obstruction in case-finding studies, allowing earlier diagnosis of COPD and acting as a better predictor of severe exacerbations and mortality than LLN.

\section{Abbreviations}

COPD, chronic obstructive pulmonary disease; LLN, lower limit normality; FR, fixed ratio; GOLD, Global Initiative for Chronic Obstructive Lung Disease.

\section{Ethical Approval and Informed Consent}

The initial and the follow-up protocol were approved by the Ethics and Clinical Trials Committee of University Hospital Mutua Terrassa and the research was conducted according the principles of the Helsinki Declaration. All patients signed their informed consent. The deceased patients and those who were lost in follow-up had granted their signed informed consent in the previous study, authorizing access to the hospital database for follow-up.

\section{Acknowledgments}

The authors thank Tania Martínez and Marta Samaniego, family medicine residents, for collaborating in the collecting of patient data from medical records, and Tom Yohannan for medical writing services.

\section{Funding}

This study won a competitive scholarship in the XIII edition of Grants of Research and Teaching Foundation Mutua Terrassa for research projects carried out in the Primary Care environment (Grant FMT 2015 Mod A). The award helped finance completion of the study.

\section{Disclosure}

Pere Almagro reports grants from AstraZeneca and SEPAR, personal fees from Chiesi, Boehringer Ingelheim, and GlaxoSmithKline, travel support from Rovi and Esteve, unrelated to the submitted study. Montse Llordés reports speaker fees from Boehringer-Ingelheim, Glaxo, and Gebro, outside the submitted work. The authors report no other conflicts of interest in this work. 


\section{References}

1. Roth GA, Abate D, Hassen Abate K, et al. Global, regional, and national age-sex-specific mortality for 282 causes of death in 195 countries and territories, 1980-2017: a systematic analysis for the Global Burden of Disease Study 2017. Lancet. 2018;392:1736-1788. doi:10.1016/S0140-6736(18)32203-7

2. Almagro P, Soriano JB. Underdiagnosis in COPD: a battle worth fighting. Lancet Respir Med. 2017;5(5):367-368. doi:10.1016/ S2213-2600(17)30133-9

3. Global Initiative for Chronic Obstructive Lung Disease - 2019. Available at: https://goldcopd.org/wp-content/uploads/2018/11/GOLD2019-v1.7-FINAL-14Nov2018-WMS.pdf. Accessed October 12, 2019.

4. Guirguis-Blake JM, Senger CA, Webber EM, et al. Screening for chronic obstructive pulmonary disease. JAMA. 2016;315(13):1378. doi:10.1001/jama.2016.2654

5. Kaplan A, Thomas M. Screening for COPD: the gap between logic and evidence. Eur Respir Rev. 2017;26(143):160113. doi:10.1183/ 16000617.0113-2016

6. Quanjer PH, Brazzale DJ, Boros PW, et al. Implications of adopting the Global Lungs Initiative 2012 all-age reference equations for spirometry. Eur Respir J. 2013;42(4):1046-1054. doi:10.1183/ 09031936.00195512

7. Turkeshi E, Vaes B, Andreeva E, et al. Airflow limitation by the Global Lungs Initiative equations in a cohort of very old adults. Eur Respir J. 2015;46(1):123-132. doi:10.1183/09031936.00217214

8. Luoto JA, Elmståhl S, Wollmer P, et al. Incidence of airflow limitation in subjects 65-100 years of age. Eur Respir J. 2016;47 (2):461-472. doi:10.1183/13993003.00635-2015

9. Woodruff PG, Barr RG, Bleecker E, et al. Clinical significance of symptoms in smokers with preserved pulmonary function. $N$ Engl J Med. 2016;374(19):1811-1821. doi:10.1056/NEJMoa1505971

10. Regan EA, Lynch DA, Curran-Everett D, et al. Clinical and radiologic disease in smokers with normal spirometry. JAMA Intern Med. 2015;175(9):1539-1549. doi:10.1001/jamainternmed.2015.2735

11. Whelton PK, Carey RM, Aronow WS, et al. 2017 ACC/AHA/AAPA/ ABC/ACPM/AGS/APhA/ASH/ASPC/NMA/PCNA Guideline for the prevention, detection, evaluation, and management of high blood pressure in adults: a report of the American College of Cardiology/ American Heart Association Task Force on Clinical Practice Guidelines. Circulation. 2018;(17):138. doi:10.1161/CIR.00000 00000000596

12. Warren B, Pankow JS, Matsushita K, et al. Comparative prognostic performance of definitions of prediabetes: a prospective cohort analysis of the Atherosclerosis Risk in Communities (ARIC) study. Lancet Diabetes Endocrinol. 2017;5(1):34-42. doi:10.1016/S22138587(16)30321-7

13. Grundy SM, Stone NJ, Bailey AL, et al. AHA/ACC/AACVPR/ AAPA/ABC/ACPM/ADA/AGS/APhA/ASPC/NLA/PCNA Guideline on the management of blood cholesterol. J Am Coll Cardiol. 2019;73 (24):e285-e350. doi:10.1016/j.jacc.2018.11.003

14. Bress AP, Colantonio LD, Cooper RS, et al. Potential cardiovascular disease events prevented with adoption of the 2017 American College of Cardiology/American Heart Association Blood Pressure Guideline. Circulation. 2019;139(1):24-36. doi:10.1161/ CIRCULATIONAHA. 118.035640

15. Llordés M, Jaén A, Almagro P, et al. Prevalence, risk factors and diagnostic accuracy of COPD among smokers in primary care. COPD J Chronic Obstr Pulm Dis. 2015;12(4):404-412. doi:10.3109/ 15412555.2014.974736

16. Castell E, Garolera D, Vilella A, et al. Adaptació al català de l'enquesta de malalties respiratories ATS-DLD-78. Validació preliminar. Ann Med. 1988;74(9):231-239.

17. Monsó E, Ribas J, Carreres A, et al. Diseño de un cuestionario ocupacional para ser utilizado en la práctica neumológica diaria. Ann Med. 1993;3:43-46.
18. GLI-2012 Desktop Software for Data Sets. Available from: http:// www.lungfunction.org/tools/90-equations-and-tools/196obtainsoftware.html. Accessed October 12, 2019.

19. Bestall JC, Paul EA, Garrod R, et al. Usefulness of the Medical Research Council (MRC) dyspnoea scale as a measure of disability in patients with chronic obstructive pulmonary disease. Thorax. 1999;54(7):581-586. doi:10.1136/thx.54.7.581

20. Soler-Cataluña JJ, Martínez-García MÁ, Sánchez LS, et al. Severe exacerbations and BODE index: two independent risk factors for death in male COPD patients. Respir Med. 2009;103(5):692-699. doi:10.1016/j.rmed.2008.12.005

21. Almagro P, Soriano JB, Cabrera FJ, et al. Short- and medium-term prognosis in patients hospitalized for COPD exacerbation: the CODEX index. Chest. 2014;145(5):972-980. doi:10.1378/chest.131328

22. Miravitlles M, Soler-Cataluña JJ, Calle M, et al. Guía Española de la EPOC (GesEPOC). Tratamiento farmacológico de la EPOC estable. Aten Primaria. 2012;44(7):425-437. doi:10.1016/j.aprim.2012. 04.005

23. Charlson ME, Pompei P, Ales KL, et al. A new method of classifying prognostic comorbidity in longitudinal studies: development and validation. J Chronic Dis. 1987;40(5):373-383. doi:10.1016/00219681(87)90171-8

24. Almagro P, Cabrera FJ, Diez J, et al. Comorbidities and short-term prognosis in patients hospitalized for acute exacerbation of COPD: the EPOC en servicios de medicina interna (ESMI) study. Chest. 2012;142(5):1126-1133. doi:10.1378/chest.11-2413

25. Miller MR, Hankinson J, Brusasco V, et al. Standardisation of spirometry. Eur Respir J. 2005;26(2):319-338. doi:10.1183/ 09031936.05.00034805

26. Roca J, Sanchis J, Agusti-Vidal A, et al. Spirometric reference values from Mediterranean population. Bull Eur Physiopathol Respir. 1986;22(3):217-224.

27. Von Elm E, Altman DG, Egger M, et al. The Strengthening the Reporting of Observational Studies in Epidemiology (STROBE) statement: guidelines for reporting observational studies. Bull World Health Organ. 2007;85(11):867-872. doi:10.2471/blt.07.045120

28. Vestbo J, Edwards LD, Scanlon PD, et al. Changes in forced expiratory volume in 1 second over time in COPD. $N$ Engl J Med. 2011;365 (13):1184-1192. doi:10.1056/NEJMoa1105482

29. Luoto J, Pihlsgård M, Wollmer P, et al. Relative and absolute lung function change in a general population aged 60-102 years. Eur Respir J. 2019;53(3):1701812. doi:10.1183/13993003.01812-2017

30. Fries JF. Aging, natural death, and the compression of morbidity. $N$ Engl $J$ Med. 1980;303(3):130-135. doi:10.1056/NEJM19 8007173030304

31. Rasmussen SH, Andersen-Ranberg K, Dahl JS, et al. Diagnosing heart failure in centenarians. $J$ Geriatr Cardiol. 2019;16(1):1-11. doi:10.11909/j.issn.1671-5411.2019.01.008

32. Ito K, Barnes PJ. COPD as a disease of accelerated lung aging. Chest. 2009;135(1):173-180. doi:10.1378/chest.08-1419

33. Arjomandi M, Zeng S, Barjaktarevic I, et al. Radiographic lung volumes predict progression to COPD in smokers with preserved spirometry in SPIROMICS. Eur Respir J. 2019;54:4. doi:10.1183/ 13993003.02214-2018

34. Celli BR, Wedzicha JA. Update on clinical aspects of chronic obstructive pulmonary disease. $N$ Engl J Med. 2019;381 (13):1257-1266. doi:10.1056/NEJMra1900500

35. Young AL, Bragman FJS, Rangelov B, et al. Disease progression modelling in chronic obstructive pulmonary disease (COPD). Am J Respir Crit Care Med. 2019. doi:10.1164/rccm.201908-1600OC

36. Eschenbacher WL. Defining airflow obstruction. Chronic Obstr Pulm Dis. 2016;3(2):515-518. doi:10.15326/jcopdf.3.2.2015.0166

37. Agustí A, Celli B, Faner R. What does endotyping mean for treatment in chronic obstructive pulmonary disease? Lancet. 2017;390 (10098):980-987. doi:10.1016/S0140-6736(17)32136-0 
38. Torén K, Andersson M, Olin AC, et al. Airflow limitation classified with the fixed ratio or the lower limit of normal and cause-specific mortality - a prospective study. Respir Med. 2018;144:36-41. doi:10.1016/j.rmed.2018.10.001

39. Odeyemi YE, Lewis O, Ngwa J, et al. Does low FEV1 in addition to fixed ratio and/or lower limit of normal of FEV1/FVC improve prediction of mortality in COPD?.The NHANES-III-linkedmortality Cohort. J Natl Med Assoc. 2019;111(1):94-100. doi:10.1016/j.jnma.2018.06.006

40. Oh DK, Baek S, Lee SW, et al. Comparison of the fixed ratio and the Z-score of FEV1/FVC in the elderly population: a long-term mortality analysis from the Third National Health and Nutritional Examination Survey. Int $J$ Chron Obstruct Pulmon Dis. 2018;13:903-915. doi:10.2147/COPD.S148421
41. Bhatt SP, Balte PP, Schwartz JE, et al. Discriminative accuracy of FEV1/FVC thresholds for COPD-related hospitalization and mortality. JAMA. 2019;321(24):2438-2447. doi:10.1001/ jama.2019.7233

42. Calverley PMA, Mueller A, Fowler A, et al. The effect of defining chronic obstructive pulmonary disease by the lower limit of normal of $\mathrm{FEV}_{1} / \mathrm{FVC}$ ratio in Tiotropium safety and performance in respimat participants. Ann Am Thorac Soc. 2018;15(2):200-208. doi:10.1513/ AnnalsATS.201703-194OC

\section{Publish your work in this journal}

The International Journal of COPD is an international, peer-reviewed journal of therapeutics and pharmacology focusing on concise rapid reporting of clinical studies and reviews in COPD. Special focus is given to the pathophysiological processes underlying the disease, intervention programs, patient focused education, and self management protocols. This journal is indexed on PubMed Central, MedLine and CAS. The manuscript management system is completely online and includes a very quick and fair peer-review system, which is all easy to use. Visit http://www.dovepress.com/testimonials.php to read real quotes from published authors. 